\title{
Apt information literacy? A case of interdisciplinary scholarly communication
}

Author:

Eystein Gullbekk,

Library, University of Oslo, Oslo, Norway and

Department of Archivistics, Information Science Department, Akershus University College of Applied

Sciences, Oslo, Norway

Eystein.Gullbekk@ub.uio.no

\begin{abstract}
Purpose: The purpose of this paper is to explore the aptness of "information literacy", conceptualized as a socially contextualized phenomenon, for analyses of interdisciplinary scholarly communication.

Design/methodology/approach: The paper presents a conceptual analysis. Two influential representatives of the social turn in the information literacy literature are taken as starting points: Annemaree Lloyd's conceptualization of "information literacy practice", and Jack Andersen's conceptualization of information literacy as "genre knowledge". Their positioning of information literacy as a socially contextualized phenomenon - by use of practice theories and rhetorical genre theory respectively - is analyzed against an illustrative example of interdisciplinary scholarly communication.
\end{abstract}

Findings: Conceptualizations by Lloyd and Andersen explain information literacy as socially contextualized in terms of stable norms and understandings shared in social communities. Their concepts have the potential of explaining changes and innovations in social practices including scholarly communication. If we combine genre-theoretical and practice-theoretical concepts - and accentuate the open-endedness of social practices and of genres - we can enhance the understanding of information literacy in settings of interdisciplinary scholarly communication where the actors involved lack shared conventions and assumptions.

Originality: The paper suggests that the fluid features of social contexts should be accounted for in the information literacy literature. By combining genre-theoretical and practice-theoretical concepts in a novel way it offers such an account. It provides a useful framework for understanding the phenomenon of information literacy in interdisciplinary scholarly communication.

Keywords: Information literacy, interdisciplinarity, scholarly communication, practice theories, genre theories

Paper type: Conceptual paper 
Eystein Gullbekk 2016. Published in Journal of Documentation, vol:72, iss:4

http://dx.doi.org/10.1108/JDOC-08-2015-0101

\section{Introduction}

Scholarly communication is dominantly studied as situated in single disciplines. However, "interdisciplinarity" has received increased attention within higher education and research over the last decade (Adkins, 2009; Thune et al., 2012), indicating that interdisciplinary scholarly communication is a growing phenomenon. Studies on scholarly communication have been grounded in various methods and theoretical viewpoints. Besides quantitative analyses of scholarly publications and citations provided by bibliometrics (e.g. Cronin and Sugimoto, 2014) a category of more qualitatively oriented social constructionist studies of scholarly communication exists. Two prominent groups of theories applied in such studies are "practice theories" (e.g. Latour and Woolgar, 1986; Pilerot and Limberg, 2011; Pilerot 2013; Sundin, 2011) and "genre theories" (e.g. Bazerman, 1985; Kjellberg, 2009). Furthermore, due to the former's influence on the latter, genres are not solely theorized as form and content, but also with reference to communicative purpose and functionality in social contexts. Genres of scholarly communication are studied as socially situated genres (Kjellberg, 2009). Concurrently the research literature on information literacy has been increasingly and equally preoccupied with explaining information literacy as a socially contextualized phenomenon. Predominantly this literature has highlighted theoretical frameworks that depict social context with an emphasis on rather stable norms, conventions and socially shared understandings or assumptions. As opposed to this, the present paper reasons that a more apt conceptualization of information literacy in situations of interdisciplinary scholarly communication must take into account that involved actors may lack shared stable conventions and assumptions. The present paper focuses on the underdeveloped potential of such accounts in current conceptualizations of information literacy.

For a concept or an understanding to be apt it needs to be pertinent to the situation to which it applies. I argue, first, that information literacy in interdisciplinary scholarly communication should be theorized with reference to practice-theoretical positions that stress social practices as open ended. We need an analytical apparatus sensitive to the constant bringing about of new connections between understandings, resources or material arrangements that hitherto have been defined as shared within communities. Second, I argue that the inclusion of genre theory in a theory of information literacy in instances of interdisciplinary communication implies agency in a way that accounts for more than just shared communicative rationalities of communities. It must also account for inventions of new genres of communication when breakdowns of shared understanding occur. I take two different representatives of the social turn in the literature as starting points for discussion: Annemaree Lloyd's (e.g. 2010a; 2010b; 2012) work on "information literacy practice", and Jack Andersen's (2006) article on "information literacy as genre knowledge".

Like many other central concepts within information studies, there is no agreed definition of the term information literacy. At a general level the term often refers to the capacity individuals need in order to find, evaluate and use information relevant to an identified information need. This capacity could be described as a set of skills or as a way of understanding the use of information (Sundin, 2008). Information literacy research, as it emerged from an interest in user education (Limberg and Alexandersson, 2009), drew on cognitive models taken from research on the information seeker working independently. Lloyd and Andersen can be read as a reaction to such perspectives, which were also reproduced by information literacy standards. In models such as the Information Literacy Competency Standard for Higher Education published by ACRL, Andersen (2006) 
Eystein Gullbekk 2016. Published in Journal of Documentation, vol:72, iss:4 http://dx.doi.org/10.1108/JDOC-08-2015-0101

has pointed out, it is as if information literacy "is considered a neutral ability to be learned and mastered by all citizens" (p. 215). He voices a trend in information studies that since the turn of the century has brought to the fore the social organization of human activities as related to the circulation and construction of knowledge. The basis of this turn as it relates to information literacy is the view that "literacy is fundamentally a social act, making literacy practices social practices" (Lupton and Bruce, 2010, p. 5).

One expression of this social turn has happened through the introduction of practice theories to information studies (Cox, 2012). When applying a practice-theoretical approach to information literacy, it "is not seen as an individual phenomenon involving an assessment of individual skills, but as a collective phenomenon, which is developed in a field of social activities and interaction" (Schreiber, 2014, p. 346). In order to understand information literacy as a socially contextualized phenomenon it is important to capture how it emerges and is learned within fields of social activities and interaction. These fields are typically articulated as particular social, occupational or disciplinary groups or domains, whether these are theorized as practice communities (Lloyd, 2010a; 2010b), discourse communities (Andersen, 2006; Simmons, 2005) or communities of justification (cf. Sundin et al., 2008). Socially organized settings of these kinds are commonly featured in the literature as stable social entities such as professional groups (e.g. doctors, nurses or scholars of different disciplines) and role groups (e.g. students or patients) (Case, 2012). The analyses focus on how such entities emerge and how they change as their organising elements, including understandings, conventions, rules, norms or roles circulate and are configured within the boundaries of fairly stable communities.

Tendencies to see information searching, sharing and use as socially organized by relational constellations described as different socially reproductive communities have been pointed out as problematic. From the perspective of organizational studies, Blackler and Regan (2009) noted that many work settings have become increasingly fluid, transitory and uncertain. Engeström (2006) pointed out that today work is often enacted by groups that intermix and reconfigure within contexts characterized by contradictions. Pilerot's (2013) study on information sharing in an interdisciplinary scholarly network demonstrates, inter alia, uncertainties grounded in a lack of core defining texts in the diverse field under scrutiny. Scholars in such networks demonstrate information literacy through interacting with a high diversity of people and material surroundings (Pilerot and Limberg, 2015). Researchers writing from the perspective of studies on higher education and research likewise note that in settings of academic research and learning disciplinary boundaries are subject to reconfigurations (Adkins, 2009). Referring to Bernstein, Adkins (2009) indicates that research practices seem to move from a state of disciplinary uniqueness and singularity, in which few external references are in play, to a state of "bringing together disciplines that may previously have existed as singulars" (p.168).

Following this development my aim is to enrich future research on interdisciplinary scholarly communication by demonstrating the aptness of information literacy conceptualizations in instances when the boundaries of traditional disciplines are challenged and negotiated by scholars participating in interdisciplinary research. This implies an understanding of how practices and changes in practices may transgress community membership. I attempt this by combing practicetheoretical and genre-theoretical considerations in a novel way. The former play a crucial role when we conceptualise genres as situated in social practices. Genres are commonly theorized with 
Eystein Gullbekk 2016. Published in Journal of Documentation, vol:72, iss:4 http://dx.doi.org/10.1108/JDOC-08-2015-0101

reference to practice-theoretical insights, as readily available structures that enable social interaction (Schryer et al., 2003). Practice theories differ, however, in that social context may be laid out as a reproductive or as an open ended relationship between structure and agency (Cox, 2012).

In the present paper I discuss the analytical consequences of differences between such theoretical emphases for conceptualizing information literacy. I take an analysis of Lloyd's and Andersen's contributions as a starting point. They are chosen by two criteria: First, they are both pioneers in introducing practice theories and genre theory, respectively, to the information literacy literature. Second, by dint of the theories they draw upon, both Lloyd and Andersen's works accommodate tension between the above-mentioned views on structure and agency. Their work exemplifies how stable communities may be given theoretical priority in conceptualizations of information literacy as well as what kinds of openings there are for theorizing information literacy as situated within uncertain community boundaries. Thus, my main question is: How do conceptual tools found within Lloyd and Andersen's practice-theoretically and genre-theoretically grounded works inform our understanding of information literacy as related to interdisciplinary scholarly communication? I approach this question by addressing three interrelated sub questions:

- In Lloyd's account of information literacy, how is social context, its stability and changeability, theorized as a function of the practice theories she applies?

- How are stability and changeability in genres accounted for in Andersen's conceptualization of information literacy?

- How can we conceptualize information literacy apt for interdisciplinary scholarly communication by combining insights from the analysis prompted by the above stated questions?

In what follows I present an illustrative example of interdisciplinary scholarly communication. I test the discussed theoretical concepts against this example throughout the paper. Then I explicate my understanding of interdisciplinary scholarly communication. I give a brief account of how the tension-ridden interplay between structure and agency is accentuated differently in practice theories and genre theories. Finally I discuss the implications of this in both Lloyd and Andersen's contributions before providing a concluding discussion.

\section{Interdisciplinary scholarly communication}

\section{Illustrative example}

A few years ago a student named "Emma" contacted me as I, at the time, was the University Library's subject librarian for a range of disciplines within the social sciences [1]. Emma had recently completed her MA in one of those disciplines. She was working as a research assistant for an interdisciplinary epidemiological project. The project involved both social scientists and medical scholars. Emma also aspired to a PhD position. She was quite optimistic as she had a main supervisor, a medical scholar, and a co-supervisor, a social scientist, at hand, both working on the project. At the time of her visit to the library, Emma was working on a systematic literature search for a literature review intended as a knowledge base for a particular publication planned by the research group. They had previously conducted a systematic search across medical databases such as PubMed and Embase. The social scientists in the group pointed to a lack in the knowledge base as there were no social science databases included. Emma's motivation for contacting me was to get help setting up a search across social science sources in addition to the medical ones. It was crucial that the search would match the 
Eystein Gullbekk 2016. Published in Journal of Documentation, vol:72, iss:4

http://dx.doi.org/10.1108/JDOC-08-2015-0101

criteria of a prior review as this served as a source of comparison. The prior work was based on the detailed taxonomy of keywords developed by the U.S. National Library of Medicine, known as MeSH terms. The taxonomy is well designed for systematic searches securing comparable results across points in time. I agreed to help her with replicating the prior search, but objected to the idea of a straightforward migration of the systematic search to other databases. My line of argument was that it would require some redesigning of the overall review, as different sources had different organizing principles embedded within them. Emma was mistrustful of my viewpoint on the matter. At her insistence we spent some time in the library's tutoring room testing out an application of the strategy across databases. She left the session in frustration. Convinced there had to be a way to "work around" the different features of different databases, she went back to the research group to "get further instructions" as she put it. Sometime later interdisciplinary research groups approached the university library, to ask for assistance in setting up a platform for publication. They had not been successful in identifying publishers suitable for their interdisciplinary reports.

\section{Epistemic objects in strong communication}

In order to explore how information literacy might be conceptualized when disciplinary boundaries are challenged in scholarly communication practices, like in Emma's case above, I need to clarify what I focus on in the broad field of scholarly communication. In the following section I provide a two-step theoretical explication of "interdisciplinary scholarly communication" against which I will scrutinize Lloyd's and Andersen's work. I first discuss the concept of "scholarly communication". Given this paper's underpinnings in practice theory, I spell out the phenomenon as situated in a socio-material context. Second, I relate scholarly communication to the concept of "interdisciplinarity". Scholarly communication may well accommodate a concept of "scholarship" based on the notion of disciplinary fields (cf. Borgman, 2007, pp. 150-151.) and hence of a communication that is organized around shared understandings, clarified norms and stabilized objects and genres. In interdisciplinary contexts, however, we need to take into account that communication might not necessarily be grounded in such mutuality.

"Scholarly communication" is often defined either as the iterative process by which scholars communicate, use and share information within their communities, or as the materialized output of scholarly research and writing (Halliday, 2001). In the first definition, "scholarly communication" denotes scholarship as an inherently social enterprise. Focus is not on materialized output but on the validation of knowledge through social interactions. Under this definition, scholarly communication encompasses the use and dissemination of information through both formal and informal genres of communication between members of a field or domain in their knowledge-productive activities (Borgman in Halliday, 2001). In Emma's case this is exemplified by oral conversations. The second definition, on the other hand, underscores materialized output while social interaction is restricted to genres by which information is formally communicated. In Emma's case these are systematic reviews, bibliographic databases, and journal articles.

This separation of materialized output and social process is problematic within a practice theoretical frame. The above-mentioned materializations of scholarly communication should be seen as multidimensional objects (Pilerot, 2014). As physical or technological objects they may function as reference points for communication among researchers and "are thereby granted a fundamental part in sociality" (p. 2008). They structure activities, bind communities together, and as objects in the making they also operate as "epistemic objects" (Pilerot, 2014). Epistemic objects, as introduced by 
Eystein Gullbekk 2016. Published in Journal of Documentation, vol:72, iss:4 http://dx.doi.org/10.1108/JDOC-08-2015-0101

Knorr Cetina (2001), are characterized by what she calls a "lack of 'object-ivity' and completeness of being" (Cetina, 2010, p. 187). In Knorr Cetina's theory of knowledge and knowing, new knowledge comes about as a result of interactions between the incompleteness of the object and scholars' efforts to figure out the object. Construed as epistemic objects, the literature review Emma is working on and the databases she utilizes are not things with a fixed quality, but rather "things that continually explode and mutate into something else" (Cetina, 2010, p. 187). In Emma's case we see that she is led to re-read the controlled indexing vocabulary in PubMed as she tries to relate it to a new environment. As epistemic objects the databases and the review point towards the not-yetdetermined conceptions and solutions that result from scholarly communication.

In the present paper I view scholarly communication as an inherently social process by which scholars figure out epistemic objects. This process includes both formal and informal genres within a field and encompasses a broad range of information-related activities - such as searching, reading/evaluating, synthesizing and sharing information - invoked for the purpose of arriving at formal written communication. Information literacy in scholarly communication within a single discipline would reflect how scholars' information-related activities are situated in relation to rules, values and understandings established and shared by historically stabilized practices or discourse communities. However, the destabilization of agreed-upon understandings brought about by the challenges posed by interdisciplinarity adds complexity to scholars' efforts to figure out epistemic objects.

Klein's (1990) influential notion of interdisciplinarity takes the integration between two or more disciplines as the defining criteria. Interdisciplinary integration concerns interaction between disciplinary components (Madsen, 2012) such as key theories, methods and seminal texts but also disciplinary assumptions and worldviews (Augsburg in Jones, 2012) that underpin actors' endeavours to figure out epistemic objects. How we conceive of the interactions that constitute interdisciplinary scholarly communication has repercussions for how we conceptualize information literacy. Two possible conceptions of interdisciplinary scholarly communication - based on Holbrook's (2013) critical review of Klein's work - are discussed below.

The first recognizes Klein's integration thesis and refers to her argument that interdisciplinarity implies "work to overcome problems created by differences in disciplinary language and world view" (Klein, 1990, p. 188). The goal of interdisciplinary integration is "an integrated framework with a common vocabulary" (Klein cited in Holbrook, 2013, p. 1870). Interdisciplinary scholarly communication can be viewed as a joint commitment to ensure "weak communication" (cf. Bataille in Holbrook, 2013). Weak communication is communication based in actors' shared tacit understanding. It involves a language that ensures "a clear understanding of the things that constitute the objective world" (Holbrook, 2013, p. 1874). Weak communication eases rational deliberations; it is ensured by shared and agreed-upon genres and shared criteria for judging one another's arguments. It enables us to agree upon truths that make it possible to coordinate activities. In Emma's case such communication is taking place in the form of the methodological correspondence taken for granted between systematic searching and systematic reviewing secured, inter alia, by the MeSH terms.

The second conception takes a different starting point. Instead of explicating conditions for integration built around consensus it seeks to explain interdisciplinarity as a process that reveals incommensurability and provokes genre invention. Genre invention emerges from "strong 
Eystein Gullbekk 2016. Published in Journal of Documentation, vol:72, iss:4 http://dx.doi.org/10.1108/JDOC-08-2015-0101

communication". Strong communication is an experience of lacking words, concepts or language in those moments when weak communication breaks down, and "when subjectivity seems unintelligible in relation to the intelligibility of [...] the objective world" (Bataille cited in Holbrook, 2013, p. 1875). In strong communication scholars adhere to different genres and hence lack shared rules of judgment, as was the case when I disputed Emma's idea of migrating searches from one database to the next. Genres determine goals towards which phrasings move (Lyotard in Holbrook, 2013) and hence what is at stake for those communicating. What is at stake in scholarly communication includes the core components of disciplines such as fundamental assumptions about, for instance, objectivity or truth. In strong communication fundamental assumptions are opened up and questioned. The initial moment of strong communication is the moment weak communication breaks down (Holbrook, 2013). The next "is the invention of a new genre of discourse, one that is not merely an integration of the previously existing genres, but a novel co-creation of those who have risked and relinquished their previous disciplinary identities" (p. 1876).

An understanding of scholarly communication as weak communication is clearly applicable to situations where scholars' joint efforts to figure out epistemic objects such as literature reviews are framed by historically stabilized disciplines, i.e. social contexts of shared rules, understandings and conventions. The integration thesis of weak communication is not a sufficient tool for capturing interdisciplinary scholarly communication. Interdisciplinary scholarly communication happens in moments of strong communication when genres become situated in destabilized social contexts. Shared conventions dissolve and new genres can be invented.

In the transitions from established to invented genres we should expect that scholars will no longer engage in information-related activities - such as Emma's effort to search systematically for literature or her research group's effort to synthesize identified literature into a publishable systematic review - as a matter of course. Even more crucially, the previously unnoticed but operational shared rules, understandings and conventions, i.e. parts of the context of these activities, become apparent. What is being addressed in the following is to what extent conceptualizations of information literacy take the destabilized context revealed by strong communication into account. When regarding information literacy as a socially contextualized phenomenon, we need to pay attention to how context is accounted for in conceptualizations of the phenomenon. Both families of theories discussed in this paper, i.e. practice theories and rhetorical genre theories, offer accounts of competing social forces that shape and frame human interaction: on the one hand, forces pushing for stability and reproduction, forces that both enable and take effect through weak communication; and on the other hand, forces pushing for innovation and change through strong communication. I shall discuss the relative weight put on competing forces in Lloyd's and Andersen's work on information literacy. Before doing so, I will in the next section clarify how I relate rhetorical genre theory to practice theories as relevant to the task of identifying the conceptual tools needed to understand information literacy in destabilized contexts of strong communication.

\section{"Genres in social practices"}

The introduction of practice theories to information studies implies that information-related activities such as seeking, searching, sharing, creating, organizing, using and communicating information are treated as socially, culturally and historically situated in relation to other human activities that make up various social settings (e.g. Lloyd, 2010a). Focus is on doings in socio-material 
Eystein Gullbekk 2016. Published in Journal of Documentation, vol:72, iss:4 http://dx.doi.org/10.1108/JDOC-08-2015-0101

contexts. Cox (2012) discusses the adoption of practice theories in information studies. The field of information behaviour research has gradually moved from a preoccupation with individualized "rational users actively pursuing a pre-given cognitive need" (p. 185) in their dealings with information to a research program addressing information and information-related activities as situated within all kinds of practices. Cox, therefore, argues that instead of simply replacing "information behaviour" with "information practice" the guiding concept for understanding the social context of information related activities should be "information in social practice" (p.186, italics added).

Genre theory is a family of theories that has been applied to theorize information and information related activities as situated in social practices (e.g. Andersen, 2006; Kjellberg, 2009; Whitworth, 2014). Rhetorical genre theory in particular draws on practice-theoretical insights. It theorizes genres as discursive events that fuse both stylistic and substantive features in response to specific situations (Schryer, 2009). As "typified rhetorical actions based in recurrent situations" (Miller, 1984, p. 159) genres are forms of social actions. They provide social actors a discursive domain with readily available structures that enable them to get work done. "They are the familiar places we go to to create intelligible communicative action with each other [...]" (Bazerman, 1997, p. 19).

The task of theorizing information literacy in cases of breakdowns of "weak communication" - the breakdowns of "the familiar places we got to" for scholarly communication - adds an extra layer to Cox' invitation to understand social actors' dealings with information as "information in social practices". First, an account of information literacy has to depart from Cox's phrasing of the problem: it would have to include, in cases of any practice, the sense of and knowledge about "what, for social actors, constitutes information, and then how do they find, use, create and share it" (Cox, 2012 , p. 185). Second, it has to deal with not only the question of how information related activities are constituted through understandings that are shared within discourse communities or practice communities. It has to deal with how epistemic objects are figured out through renegotiations of shared understandings and conventions when information-related activities are situated in strong communication and when genre invention may occur. This demands of us a closer look at the potentially different explanatory power inherent to genre and practice theoretical concepts of context in terms of accounting for such renegotiations.

Along with Carolyn Miller, Bakhtin serves as a basis for making rhetorical genre theory concerned with genres in their social context (Schryer, 2009). In Bakhtin's genre theoretical terminology every utterance belongs to a genre. Any utterance receives its expressivity by dint of the genre within which it is uttered (Bakhtin et al., 1986, p. 87). In much the same way as Miller's "typified rhetorical action", Bakhtin's conception of genre draws our attention to communication as occurring in typical situations. Within these situations, genres may be subject to "centripetal processes" (Bakhtin et al., 1981, p. 272; cf. Whitworth, 2014; Foscarini, 2012) by which social forces pull utterances towards the centre to keep them stable and aligned with the genre. It is a social process that ensures that utterances conform to conventions and norms in a social sphere of communication. At the same time, however, utterances are subject to "centrifugal processes" (Bakhtin, 1981, p. 272; cf. Whitworth, 2014; Foscarini, 2012). They may be "'pushed out' to individual speakers interacting within networks and communities, exploring ideas and forming knowledge 
Eystein Gullbekk 2016. Published in Journal of Documentation, vol:72, iss:4

http://dx.doi.org/10.1108/JDOC-08-2015-0101

polyphonically" (Whitworth, 2014, p. 138). Individual utterances can resist ready genres and push for invention and reshaping.

However, genre theories do not in themselves explain change in, or invention of, new genres (Eriksson et al., 2009). To this end, practice theories are added with their potential to highlight either side of this contextual dynamic of communication. Practice theories conceptualize "context" through different deliberations of the mutual constitution of structure and agency (Moring and Lloyd, 2013; Feldman and Orlikowski, 2011). In turn these different deliberations serve different understandings as to how agency may reproduce or transgress community boundaries, stabilize or bring about changes in practices and, particularly relevant to this paper, bring about genre invention situated in practices. In theorizing information literacy with reference to having knowledge about situated genres, as we shall see is the case in Andersen, we may put relative stress on the tension-ridden interplay between centripetal or centrifugal processes. A critical question in the following is therefore how "social context" is conceptualized in different practice theories, and how these differences are weighted in conceptualizations of information literacy.

What is at stake in the case of information literacy in interdisciplinary settings is how epistemological categories such as information, knowledge and meaning are linked up with boundary categories such as fields, domains or communities, and how agency is conceptualized in order to explain change in practices and invention of genres. I turn first to Lloyd's conceptualization of "information literacy practice" and then to Andersen's conceptualization of information literacy as "genre knowledge" to discuss the consequences different accentuations of concepts have for the task of capturing interdisciplinary information literacy.

\section{A practice theoretical conceptualization}

Annemaree Lloyd's work on information literacy has been valued as a successful introduction of practice theory to the literature on information literacy and information behaviour (Cox, 2012, p. 185; Schreiber, 2014). Lloyd invites us to understand information literacy as a complex socio-cultural practice. She outlines a research program that implies further research into the social enactment of information literacy in particular social settings. In her work on information literacy among emergency workers, she applies concepts taken from socio-cultural perspectives on human activity, Wenger's conceptualization of communities of practice as applied within studies on workplace learning, and Schatzki's site ontology (Lloyd, 2010a). Lloyd has pointed out that the practice theories developed by these two authors feeds different analytical strategies (Moring and Lloyd, 2013). Whereas the first draws our attention to competent participation within communities of practice, the latter focuses on how practices emerge through actors' sayings and doings. As she herself draws on both, her conceptualization of information literacy provides an interesting case of analysis. By looking at Lloyd's conceptualization I will first demonstrate how the accentuation of particular practice-theoretical accounts of social context may underpin how information literacy features as intrinsic to the stabilizing forces of communities and their boundaries. Then I will scrutinize how practice-theoretical concepts that are present in her work may be opened up to help understand changes in practices across community boundaries. Throughout the discussions I place Wenger's "communities of practice" in the first instance, and Schatzki's conceptualization of the "site of the social" in the second, fully aware that this to some extent represents a caricature of their rich theoretical contributions, and their influence on Lloyd's writings. 
Eystein Gullbekk 2016. Published in Journal of Documentation, vol:72, iss:4

http://dx.doi.org/10.1108/JDOC-08-2015-0101

\section{Information literacy practice}

Lloyd (2010a; 2010b) introduces a specific metaphor: "the information landscape". An information landscape will consist of texts (books, articles, webpages, or any other text that embodies valued experience of a practice community) and non-textual resources (that would include tools and technology, ways of thinking, established interpretations and, as Lloyd strongly emphasizes, bodily movement). Lloyd shows that information literacy is both a reproductive social process that maintains information landscapes through members' participation in communities of practice, and the ability participants develop in order to read the information landscape within which they "work, live or play" (Lloyd, 2010a, p. 30). An information literacy practice is composed of the activities through which people become related to different modalities of information that constitute the landscape. An information literacy practice is thus a set of enacted relations. This set is shaped by "the socio cultural and material affordances furnished by the site, its actors and objects" (Lloyd, 2010a, p. 43). Lloyd stresses that actors' doings and sayings and the way these relate to an information landscape are organized towards particular social projects (Lloyd, 2012, p. 775). Together this organised feature of practices structures the information landscape through which participants access information and become part of learning processes.

In Lloyd's work, "information" is understood and treated according to Bateson's definition as "any difference which makes a difference" (Lloyd, 2010b, p. 247). Drawing on this definition, it becomes pivotal to analyze how difference comes to make a difference, that is to say, how entities we label information (be it a bodily movement, a piece of text or an artefact) come to mean something. To Lloyd this means that information "must be situated and made intelligible through the contextual lens of social life" (p. 247). By framing information literacy with a practice-theoretical apparatus we are, according to Lloyd, enabled to understand an information-literate person "[...] as an expert user of information who, through their information practice, develops a deep connection with their information landscape, a fluency with the modalities of information valued within it [...]" (Lloyd, 2010a, p. 30).

\section{Stabilizing communities}

In her studies of emergency workers Lloyd (2010a) demonstrates how different modalities of information landscapes interrelate in the construction of domain-specific knowledge. Both textually, socially and corporeally mediated information play important parts. The activities through which these modalities are negotiated by the workers are theorized in line with Wenger's theory of communities of practice. In Wenger's theory learning and identity formation play leading roles. By these two concepts he stresses the active role participants have in the continuous reinvention of social practices (Cox, 2012, p. 180). They draw our attention to "the social group that can form through common active participation in a practice" (Cox, 2012, p. 180).

Learning is the process in which the socially recognized corpus of knowledge and competencies of a particular community is negotiated in relation to participants' experiences or personal views. Communities' shared tools, concepts and narratives are produced and reproduced through negotiations of meaning through learning processes (Brown and Duguid, 1991). A profound concept in seeing learning as such negotiations is that of "legitimate peripheral participation" (Wenger, 1998, p. 100). The concept refers to varying degrees of ownership of categories of meaning as these are sanctioned within particular communities of practice. In Lloyds account the social mediation of information is crucial for negotiations of participants shared understandings. It is by 
Eystein Gullbekk 2016. Published in Journal of Documentation, vol:72, iss:4 http://dx.doi.org/10.1108/JDOC-08-2015-0101

relating subjective observations and understandings to the collective information of the community that newcomers are drawn from the periphery towards the centre of the community. Newcomers must learn from the more experienced members of the established community, and typically do so by initially contributing to more peripheral aspects of the practice before moving closer to the centre.

In our example Emma is participating in one of the peripheral, but legitimate, aspects of a literature review, namely the systematic search. In doing so, her goal could be to move closer to the centre of the community by first being accepted as a PhD student and eventually perhaps establishing herself as a working scholar. Emma's legitimacy as a member of the scholarly community may increase as she moves towards the centre of the practice and increasingly identifies herself with the community in question. In Lloyd's (2010a) account this trajectory would encompass information related activities that would direct Emma towards information modalities that embed the collective knowledge of her community. Emma's senior is directing her to particular bibliographic indexes deemed relevant for a systematic review. What information that is shared within her community of practice is afforded by the particular organized sets of sayings and doings of the community. This social organisation influences how Emma couples information and thereby reproduces information practices that are sanctioned by her community.

Learning is also a process in which novices develop and negotiate their identity or workplace subjectivity (Lloyd, 2010a), in relation to their community of practice. Identity formation is intrinsic to learning processes. There is of course far more to this process than mere replication of prescribed identities. In their widely cited article on the relationship between work and learning in processes of innovation, Brown and Duguid (1991) illustrated the quality of fluidness in Wenger's concept of community. In their phrasing, communities of practice "[...] are emergent. That is to say their shape and membership emerges in the process of activity, as opposed to being created to carry out a task" (Brown and Duguid, 1991, p. 49). Communities emerge as they respond to changing environments, changes that may push practices in directions that divert from the canonical accounts or designs provided by institutions or organizations within which they operate. One mechanism of change in this emergence is that newcomers, in the process of becoming legitimate participant at the centre, get caught in a dilemma (Fox, 2000):

On the one hand, [participants] need to engage in the existing practice, which has developed over time: to understand it, to participate in it, and to become full members of the community in which it exists. On the other hand, they have a stake in its development as they begin to establish their own identity in its future (p. 856).

The epistemological category of meaning is connected with learning and identity formation. Wenger theorizes context as community of practice and identifies learning and identity formation as central concepts of agency. These are processes that at the same time account for change in practices and for the reproduction and stabilization of the group or community of practice within which the practice exists. Thus, Wenger accentuates change but within the boundaries of the community as attention is drawn "to the common ground and perspectives that people who engage in a practice (sometimes?) have," (Cox 2012, p. 180).

In Lloyd's work, information landscapes, and the way participants relate with them, are configured within particular practice communities. Information landscapes reflect agreed upon 
Eystein Gullbekk 2016. Published in Journal of Documentation, vol:72, iss:4 http://dx.doi.org/10.1108/JDOC-08-2015-0101

sources that "constitute the intersubjective agreement that informs our situated realities" (Lloyd 2012, p. 773). Information literacy is both production and the outcome of it. On the one hand, it is through information literacy practices that participants become co-constitutive to the practices of particular communities. On the other hand, and simultaneously, information literacy is the capacity of the information literate to read and draw upon the information landscape as sanctioned by his or her practice community. Linked up with Wenger's concept of communities of practice - in which practice is conceptualized as intrinsic to community - information literacy practice is most strongly expressed as reproduction and maintenance of social context understood as particular and bounded practice communities. In order to theorize information literacy in relation to interdisciplinary scholarly communication we must give "practice" a theoretical priority over "community", and construe the information literate's knowledge of situated genres by linking this knowledge up with a practice-theoretical strand that puts more stress on open-endedness. I here turn to Schatzki.

\section{Changes in practice-order bundles}

Schatzki is granted a prominent place in Lloyd's conceptualization of information literacy, which "is philosophically anchored by the concept of site ontology" (Lloyd, 2010a, p. 33). Schatzki (2002) elaborates context, which he defines as "the site of the social", differently than Wenger does; he understands context as "community of practice".

The site of the social does not grant priority to actions in local context. In Schatzki's (2005) view practices are "organized, open-ended spatial-temporal manifold of actions" (p. 471). Emma's literature review, for example, does not take place in the library, the seminar room, her office or those of her supervisors. Instead, it coheres as meaningful by dint of practices and material arrangements that constitute each other. "Practices" are the open-ended sets of doings and sayings organized by shared understandings. Practices are held together by three phenomena (Schatzki, 2002; Schatzki, 2005, p. 471): "practical understandings" (e.g. how to utilize MeshTerms in a PubMed-search for the purpose of systematic reviewing), "rules" (e.g. following certain procedures to ensure comparability between systematic reviews at different points in time) and "teleoaffective structures" (i.e. the normative component of practices, such as Emma's ambition to further her career by working on the systematic search). "Material arrangements" are entities - people, artefacts, things, organisms linked together by an infinite number of types of relationships (Schatzki 2005 cf.; Cox, 2012, p. 177). Practices are inseparable from material arrangements. They use, alter and affect such arrangements. Material arrangements, in turn, channel, prefigure and facilitate practices (Schatzki, 2011, p. 4). For instance, the library's tutoring room with its large screen computers, facilitated the collaborative search session in the different databases. Practices and arrangements form bundles that in concert constitute the site of the social. Within this practiceorder bundle agency is conceptualised not as learning as in Wenger, but as practical intelligibility (Farrugia, 2013). Practical intelligibility points to ways in which the world is made meaningful to us by our acting within it. It is the clearing in which we are enabled to act, do, utter or reflect. Practical intelligibility sorts out acts that practical understanding in turn carries out (Gram-Hanssen, 2007).

The stress put on open-endedness implies a constant potential of change in practices, of the emergence and rearrangements of practice-order bundles. Even small changes across the bundles may change practices over time: 
Eystein Gullbekk 2016. Published in Journal of Documentation, vol:72, iss:4

http://dx.doi.org/10.1108/JDOC-08-2015-0101

The emergence of a bundle is the establishment of one or more activity manifolds that conjointly transpire amid a particular arrangement or set of arrangements. This process can involve, among other things, the coalescence of organized activities (including the crystallization of common rules, teleologies, and understandings), the erection of links between previously unconnected practices or arrangements, the appropriation or production and introduction of material entities and arrangements, the bifurcation of an extant bundle into descendent bundles that develop separately, the hybridization of extant bundles into a new bundle, the accumulation of small changes over time, and the crystallization of bundles around people or things. (Schatzki, 2011, p. 7)

Changes in practices, and the bundled practice-orders, are seen as the emergence of new combinations of doings and sayings, their organizing principles - the understandings, teleologies and rules - and of the entities of material arrangements. Relational changes between practices and arrangements and between their constituent parts bring about new negotiated meanings of acts and entities and importantly, new "links between previously unconnected practices or arrangements". In Emma's instance, the meaning of the different genres in the genre system of doing a literature review, the technological functionalities of the different databases applied and the doings of the searching are all part of meaning-producing practices; meaning is negotiated in the enactment of a literature review. In the example, however, the coherent meaning ensured by the relational positioning seemed to crack, and Emma expressed a need "to work around" different features of the different tools available to her.

In keeping with Schatzki's site ontology, Lloyd implies that what counts as information or not, how information is sanctioned and valued, is reflected in the activities (the sayings and the doings) and in the relating of people and of material arrangements. This is, as we see, open-ended, not in terms of the reproduction of particular practice communities, but as the community-transgressing emergence of new practice-order bundles. For the task of conceptualizing information literacy in interdisciplinary scholarly communication we need to bring this open-endedness to the fore. Openendedness, however, challenges how we theorize genres as situated in practice, and how we conceptualize genre knowledge as necessary for purposeful, scholarly communication. I now turn to the possible consequences of the alternative practice-theoretical views of social context - with emphasis on either a reproductive or an open-ended relationship between structure and agency - for situating genres and genre knowledge in interdisciplinary scholarly communication. I do so by introducing and discussing Andersen's conceptualization of information literacy as genre knowledge.

\section{Information literacy as genre knowledge}

The concept of "genre knowledge" was introduced by Berkenhotter and Huckin (1995). To them genre knowledge "embraces both form and content, including the sense of which content is appropriate to a particular purpose in a particular situation at a particular point in time" (Berkenhotter \& Hucking, 1995, p. 13). Andersen (2006) elaborates the concept further in his discussion of genre knowledge as information literacy. In his article "The public sphere and discursive activities: information literacy as sociopolitical skills", Andersen (2006) aims to provide a genretheoretical analysis of what information literate actors would need to know to seek information in systems of organized knowledge. Documents stored in systems are produced by someone for somebody. They are invested with particular purposes and interests. Knowledge about sources, as well as our activities of seeking them out and applying them to our own work, is therefore "preconditioned by an understanding of how knowledge is socially organized in society" (Andersen, 
Eystein Gullbekk 2016. Published in Journal of Documentation, vol:72, iss:4 http://dx.doi.org/10.1108/JDOC-08-2015-0101

2006, p. 216). Information literacy must be understood accordingly. His main line of reasoning is as follows:

First, information literacy can be seen as degrees of the information seeker's insight into "the rhetorical situation" within which the information seeker is situated, i.e. "the interaction between the elements writer, purpose, audience, subject and context" (Andersen, 2006, pp. 217-218). Second, drawing on Habermas' theory of the public sphere and its ancillary communicative rationality, the rhetorical situation is seen as structured within and by discourse communities and their textual mediations of knowledge as discursively organized at the societal level. The public sphere evolved as a sphere for debate that produced a distance between the sphere of the state and the sphere of the private. In its ideal form the public sphere is free from suppressing structures such as class position or gender, and the emergence of this communicative sphere serves as the prerequisite for democratic processes. Each sphere produces its own communicative means and its own documents and genres "as responses to the communication interests in the various spheres and domains in society and state" (Andersen, 2006, p.221). Thus third, information literacy theorized as genre knowledge refers to information seekers' knowledge about documents and their social organization. The social organization of documents relates to norms regulating genre features such as writing style, epistemology, ideology or vocabulary. The information literate possesses knowledge about how such norms are legitimized within discourse communities.

In Andersen's account information literacy encompasses both technical skills, and more importantly, a critical interpretative capacity. Information literacy is the capacity to step back and look beneath the surface of discourse and to apply this understanding to documents stored in electronic information systems. But it is more than the capacity to interpret backwards. Situated in the rhetorical situation, the information seeker is likely to use information in further communication with an audience. The knowledge that documents are products of intentions, interests and purposes of discourse communities, is also applicable to one's ability to act communicatively within spheres of activities shaped by the production and use of documents. Information literacy is the ability to discursively act upon domains configured and mediated by genres. It is the capacity to link information up in arguments that work purposefully in the presence of one's peers with whom one shares membership in particular discourse communities. To be literate in genres, to possess genre knowledge, increases our access to the resources they offer, and makes us more capable of purposefully applying information to communicative acting: "information Literacy becomes equivalent to genre knowledge" (Andersen 2006, p. 225).

\section{Stabilizing communities, again}

"Discourse communities" are characterized by "members having shared rules of producing and reading texts and ways of acting discursively" (Andersen, 2008, p. 350). In Andersen's account genres hold discourse communities together. He puts it as strongly as saying they are their "glue so to speak" (Andersen, 2008, p. 350). Two points about genre knowledge are crucial in Andersen's discussions of information literacy as genre knowledge. First, that it is characterized by the capacity of reading collective intentions and purposes as originating from discourse communities (Andersen, $2006 ; 2008)$. Andersen puts stress on genres as subject to centripetal processes by which social forces pull utterances towards the centre to keep it stable and aligned with the genre. Second, that the relationship between the individual (utterer) and the collective (discourse community) is one of socialization. Andersen here refers to insights from socio-cultural learning theory and activity theory. 
Eystein Gullbekk 2016. Published in Journal of Documentation, vol:72, iss:4 http://dx.doi.org/10.1108/JDOC-08-2015-0101

Genres are tools available to participants from the toolkit of a field of activity (Andersen, 2008). Participants interacting within an activity system invoke and appropriate interrelated genres - genre systems (Bazerman in Andersen, 2008).

Situated in the rhetorical situation, information literacy includes the capacity of linking up information in arguments that are effective in a particular discourse community. Genres provide participants with the sense of structure needed to get the work of communication done (Schryer et al., 2003, p. 91), and serve "as institutionalized templates for social interaction" (Levina and Orlikowski, 2009, p. 675). Genre theory seems appropriate if one is to illuminate the communicative aspects that stabilize practice communities around common ground and perspectives. Genres represent stabilizing structures for the meaning negotiations that reproduce communities through processes of learning. In Wenger practices are linked to the social group that is engaged in forming a community of practice within which people share discourses and interpretative matrices, or one could say, genres that reflects a joint enterprise, shared perspectives and shared purpose. In this sense, genres mediate the information landscape of particular communities. As recurrently enacted structures, genres contribute to the identity of a given practice community and facilitate learning as newcomers develop workplace subjectivity on their journey towards participation at the centre of a discipline.

Hence, Andersen (2006) and Lloyd (2012, 2010b) - when she links information literacy up with Wenger's "community of practice" - both offer a view on information literacy that theorizes context intrinsically with socially bound collectives, as communities of practice and discourse communities. Both stress information literacy as simultaneously production and outcome, based in joint understanding and mutual intelligibility. Both account for the inter-subjectivity that underpins weak communication. This allows a specific kind of theoretical coherence in conceptualizations of information literacy as literacy in situated genres: As we saw in the example, Emma related to resources and modalities in the information landscape invoked by the practice of producing a literature review. Following Lloyd the information literacy practice revolves around her senior comembers mediation of the formal environment to newcomers (cf. Lloyd, 2012, p. 779). Through the influence of Emma's seniors, certain resources that are present in the information landscape of her work setting are pointed out to her. The genre system of a literature review (in this case bibliographic databases, systematic literature searching and systematic reviews to be formally published) is part of the mediated environment available in her work setting. By mastering the resources as part of this genre system she relates to other members of the community and to shared understandings of the reasonability of joint purposes. This situated genre knowledge fits well with the thesis of consensus in interdisciplinary communication (cf. Holbrook, 2013).

\section{Genre invention in changing practices}

However, in the interaction taking place in Emma's case, the underlying communicative rationality of the genre system in this particular rhetorical situation becomes questioned. The appropriateness of different tools and stored texts to a systematic review is experienced as uncertain. Communicative conflicts and breakdowns occur. The challenge posed to us when we theorize interdisciplinary information literacy becomes how to account for negotiations of such breakdowns and the genre knowledge needed to engage in the strong communication (cf. Holbrook, 2013) occurring in settings of uncertain and unshared understandings. 
Eystein Gullbekk 2016. Published in Journal of Documentation, vol:72, iss:4 http://dx.doi.org/10.1108/JDOC-08-2015-0101

Referring to Bakhtin, Andersen (2008) stresses the addressivity of utterances within the genre as linked with the intentionality of communication that is embedded in "shared rules of producing and reading texts and ways of acting discursively" (p. 350). Genres may, however, also be characterized by their open-endedness. Bakhtin does stress that "each sphere has and applies its own genres that correspond to its own specific conditions" (Bakhtin, 1986, p. 64). At the same time he also stresses that utterances always anticipates a response that is not yet determined (Bakhtin, 1986). Schryer (2009) argues that genres are not solid structures reified for stable consensus underlying communication taking place within discourse communities. Rather they should be seen as only "stabilized-for-now or stabilized enough sites of social action" (Schryer, 2009, p. 1936). Genres are only the "'stabilized-for-now' outcomes of an ongoing process of interpretation that comes from the collective action of reflexive human actors" (Foscarini, 2012, p. 397). These collective actions are "caught between stabilization and de-stabilization" (Andersen, 2015, p. 35). In the case of Emma and her research group we should be able to ask in how far new emerging genres replicate genres that originate from particular disciplinary traditions, and in how far they are inventions emerging from strong scholarly communication.

Genres could be analysed as part of the study of changes in practice-order bundles by a focus on "their centrifugal activities and their outcome" (Foscarini, 2012, p. 396). To what extent do individual utterances resist ready genres and push for invention and reshaping? Through an analysis of students working on written assignments, Trine Schreiber (2014) points us partly in the direction of an analysis of how genres as subject to centrifugal forces are intertwined with changes in practices. Schreiber refers to genre characteristics of scholarly articles, described by Bazerman (1988) as possible regularities of writing practices. She compares these regularities with the configuration of written assignments as observed in the activities of a group of students. According to Schreiber, the configurations show that both regularities and irregularities occur, and that changes in writing practices follow changes in, and different applications of, the organizing phenomena of rules and understandings. Her analysis points to social regularities as constantly in the making, or, in Schatzki's words, open-ended. Schatzki urges us to "pay particular attention to the chains of actions that link and pass through bundles and nets" (Schatzki, 2005, p. 476). But how do changes in practice-order bundles lead to genre invention? The analysis could be extended to look at how configurations emerge across practices by "the erection of links between previously unconnected practices or arrangements" (Schatzki, 2011, p. 7).

\section{Closing discussion}

Theories of information literacy typically are composite theories. Depending on our analytical objectives, it is crucial to pay attention to how we accentuate the concepts we borrow from supporting theories, in this case practice theories and rhetorical genre theory. My aim in this paper has been to identify concepts that are apt for understanding information literacy in settings of interdisciplinary scholarly communication. These are settings where actors' shared understandings may crack in situations of strong communication. In practice-theoretical terms, I argue, we here need to account for interdisciplinary scholarly communication in ways that do not theorize context as identical to entities such as social groups or particular communities. This view is in line with McKenzie (2015) who points out that "genre, information, and context are not themselves fixed entities" (p. 86). Interdisciplinary information literacy encompasses the role of social actors in 
Eystein Gullbekk 2016. Published in Journal of Documentation, vol:72, iss:4

http://dx.doi.org/10.1108/JDOC-08-2015-0101

reworking social context, or the structural contours of their social life (Feldman and Orlikowski, 2011, p. 1241), engaging in practices that cross social groups or communities.

Following the social and practice turns in the information literacy literature, information literacy concepts have been developed as analytical tools for understanding the relationship between such phenomena as learning, identity development or communicative purposefulness and information-related activities within various communities. In Lloyd's (2010a, 2012) work "information literacy practice" is seen as emerging and learned in social context, but emphasis is on context conceptualized as the reproductive relationship between structure and agency within communities of practice. In Andersen's (2006) work "genre knowledge" correspondingly describes the capacity needed to act with communicative purpose and adequacy within discourse communities that are mediated through structuring templates for social action, namely genres.

Andersen and Lloyd represent a turn in the literature that in part can be read as a critique of research that has focused on information literacy at the level of individual information seekers and as neutral to social contextual factors. Information literacy research after the social and practice turns refutes such neutrality, and the focus on particular occupational or social groups has served to prove a point. Lloyd's work belongs with contributions that explain information literacy as a socially contextualized phenomenon, in practice-theoretical and socio-cultural research traditions including Sundin's (2002) work on nurses; Schreiber's (2014) analysis of information literacy practices of student groups; or Tuominen, Savolainen and Taljas (2005) elaborations of the situatedness of information literacy.

Discourse analytical work on information literacy has taken a critical stance towards historical formations of information, knowledge and ways of understanding information literacy, for instance as institutionalized through competency standards. Notable examples are the critical analysis of information literacy discourses in school libraries (Kapitzke, 2003), and Pawley's (2003) argument that information literacy needs to address "context and content in understanding how information 'works'" (p. 448). Through his concept of information literacy as genre knowledge, Andersen has turned such critiques of discursive interpretative schemes into an interpretative capacity of actors in their purposeful communication of information to fellow members of particular discourse communities.

In instances where the boundaries of particular communities, be it disciplines or occupational groups, become looser, and shared understandings seem to dissolve somewhat, context is not preconfigured through such entities. This calls for a stronger accentuation of the open-ended relationship between structure and agency in our composite theories of information literacy. We do not only deal with the question of how information-related activities are constituted through shared understandings within discourse communities or practice communities. As related to cases of interdisciplinary scholarly communication we also deal with how efforts to figure out epistemic objects emerge through renegotiations of understandings in situations of strong communication and within changing practice-orders.

An apt conceptualization of information literacy in interdisciplinary scholarly communication takes this open-endedness of practices - the volatile connections between understandings and resources or material arrangements - into account at three interrelated levels.

The first level is that of the individual scholar's enactment of information literacy. In interdisciplinary cases, with their moments of strong communication, information literacy would still 
Eystein Gullbekk 2016. Published in Journal of Documentation, vol:72, iss:4

http://dx.doi.org/10.1108/JDOC-08-2015-0101

include the interpretative capacity of the scholar to "look beyond discourse" when placed in "rhetorical situations" (Andersen, 2006). An understanding of the development of this capacity, however, needs to accentuate the centrifugal forces inherent in working genres. Working genres may push communication towards regularity, convention and stability. But they may also push for resistance and invention within and across practices. Not only do actors like Emma have to develop the genre knowledge needed to access and communicate information as it is regulated through a given discourse community (in her case by contributing to a literature review), they also have to relate to the centrifugal forces of genres as these are invoked through conflicting rules, understandings and teleoaffective structures of crossing practices. Information literacy would include the capacity to anticipate genre inventions based on how practices change and evolve through relational changes between practices and material arrangements and between their constituent parts. Individuals are the "unique crossing point of practices" (Reckwitz in Schreiber 2014, p. 350) and, according to Schreiber (2014), this gives them the capacity to adjust and change their ways of doing things within the practices. An understanding of this capacity should account for how doings and sayings are carried out according to what occur to the actor as meaningful and practically intelligible in situations of strong communication.

The next level is that of practice itself. If being information literate means being an expert user of information "who, through their information practice, develops a deep connection with their information landscape" (Lloyd, 2010b, p. 30), then this information practice must accommodate responsiveness to the layers that hitherto have been treated as tacit dimensions of information practices. Negotiations of the conflicting rules, understandings and teleoaffective structures of crossing practices - silent dimensions in weak communication that become exposed in strong communication - must be part of the interdisciplinary practices of figuring out epistemic objects.

The final level is that of our conceptualizations of information literacy. Apt conceptualization avoids replacing practical logic with theoretical logic. In the case of interdisciplinary scholarly communication, as discussed in this paper, genre invention, invoked by "the erection of links between previously unconnected practices or arrangements" (Schatzki, 2011, p. 7), emerges as a consequence of the everyday performance of information-related activities by actors such as Emma. Since the practice turn in the information behaviour literature, it is this ontological primacy of practice that we have built into our theoretical concepts (cf. Feldman and Orlikowski, 2011). Also conceptualizations of information literacy need to recognize the mutuality between theoretical and practical logic. Our further conceptual elaborations must be informed by rubbing our concepts against the state of flux of the socio-material world that we seek to understand.

In this paper I have explored concepts to enhance an understanding of information literacy in interdisciplinary scholarly communication. Theories and concepts, however, are never brought to a conclusion. Apt conceptualization of information literacy is contingent on a continuous reflexivity between the three levels. This recognition provides a basis for future research.

\section{Acknowledgements}

Thanks are due to Katriina Byström for her guidance and input, and to Ola Pilerot for valuable comments on an earlier version. Hege Kristin Ringnes, Andrea Gasparini, Therese Skagen, Atle Wehn Hegnes and Sidsel Lied all gave inspiring responses. The author also acknowledges the anonymous reviewers for their useful comments. This work has partly been made possible through a leave 
Eystein Gullbekk 2016. Published in Journal of Documentation, vol:72, iss:4

http://dx.doi.org/10.1108/JDOC-08-2015-0101

granted by the author's employer, The University of Oslo Library and is part of his doctoral work at Oslo and Akershus University College of Applied Sciences.

\section{Notes}

1. "Emma" represents a synthesis of several similar library inquiries at that time.

\section{References}

Adkins, B. (2009), "PhD pedagogy and the changing knowledge landscapes of universities", Higher Education Research and Development, Vol. 28 No. 2, pp. 165-177.

Andersen, J. (2006), "The public sphere and discursive activities: information literacy as sociopolitical skills", Journal of documentation, Vol. 62 No. 2, pp. 213-228.

Andersen, J. (2008), "The concept of genre in information studies", Annual Review of Information Science and Technology, Vol. 42 No. 1, pp. 339-367.

Andersen, J. (2015), "Re-describing knowledge organization - A genre and activity-based view", in Andersen, J. (Ed.), Genre theory in information studies, Emerald, Bingley, pp. 13-42.

Bakhtin, M., Holquist, M., and Emerson, C. (1981), The dialogic imagination : four essays, University of Texas Press, Austin, TX.

Bakhtin, M., Holquist, M., Emerson, C., and McGee, V. W. (1986), Speech genres and other late essays, University of Texas Press, Austin, TX.

Bazerman, C. (1985), "Physicists reading physics schema-laden purposes and purpose-laden schema", Written communication, Vol 2 No 1, pp. 3-23.

Bazerman, C. (1988), Shaping written knowledge : the genre and activity of the experimental article in science, University of Wisconsin Press, London.

Bazerman, C. (1997), "The life of genre, the life in the classroom", in Bishop, W. and Ostrum, H. (Eds.), Genre and Writing, Boynton/Cook, Portsmouth, NH, pp. 19-26.

Berkenkotter, C. and Hucking, T.N. (1995), Genre knowledge in disciplinary communication: Cognition/Culture/Power, L. Erlbaum Associates, Hillsdale, NJ.

Blackler, F., and Regan, S. (2009), "Intentionality, agency, change: practice theory and management", Management Learning, Vol. 40 No. 2, pp. 161-176.

Borgman, C.L. (2007), Scholarship in the digital age: information, infrastructure, and the Internet, MIT Press, Cambridge, MA.

Brown, J. S., and Duguid, P. (1991), "Organizational learning and communities-of-practice: Toward a unified view of working, learning, and innovation". Organization science, Vol. 2 No. 1, pp. 4057.

Case, D. O. (2012), Looking for information : a survey of research on information seeking, needs, and behavior, Emerald, Bingley.

Cetina, K. K. (2001), “Objectual practice”, in Schatzki, T. R. Cetina, K.K. and Savigny, E. v. (Eds.), The Practice turn in contemporary theory, Routledge, London, pp. 175-188.

Cetina, K. K. (2010), "The Epistemics of Information A Consumption Model", Journal of Consumer Culture, Vol 10 No. 2, pp. 171-201.

Cox, A. M. (2012), "An exploration of the practice approach and its place in information science", Journal of Information Science, Vol. 38 No.2, pp. 176-188.

Cronin, B. and Sugimoto, C. R. (2014), Beyond bibliometrics: harnessing multidimensional indicators of scholarly impact, The MIT Press, Cambridge, MA.

Engestrom, Y. (2006), "From well-bounded ethnographies to intervening in mycorrhizae activities", Organization Studies, Vol. 27 No. 12, pp. 1783-1793.

Eriksson, C. I., Akesson, M., Bergquist, M., and Ljungberg, J. (2009), "Forming a value networkanalyzing the negotiations between actors in the e-newspapercase", in 2009 Proceedings of 
Eystein Gullbekk 2016. Published in Journal of Documentation, vol:72, iss:4 http://dx.doi.org/10.1108/JDOC-08-2015-0101

the 42nd Hawaii International Conferenceon on System Sciences, Waikoloa, Hawaii, 5-8 January.

Farrugia, D. (2013), "The reflexive subject: Towards a theory of reflexivity as practical intelligibility", Current Sociology, Vol. 61 No. 3, pp. 283-300.

Feldman, M. S., and Orlikowski, W. J. (2011), "Theorizing practice and practicing theory", Organization Science, Vol. 22 No. 5, 1240-1253.

Foscarini, F. (2012), "Diplomatics and genre theory as complementary approaches", Archival Science, Vol. 12 No. 4, pp. 389-409.

Fox, S. (2000), "Communities of practice, Foucault and Actor-Network Theory", Journal of management studies, Vol. 37 No. 6, pp. 853-868.

Gram-Hanssen, K. (2007), "Practice theory and the green energy consumer". Paper presented at the Annual Conference of the European Sociological Association, 3-6 September 2007, Glasgow, UK, available at: http://www.esa-consumption.org/papers/gramhanssen.pdf (accessed 20 january 2015).

Halliday, L. (2001), "Scholarly communication, scholarly publication and the status of emerging formats", Information Research, Vol. 6 No. 4.

Holbrook, J. B. (2013), "What is interdisciplinary communication? Reflections on the very idea of disciplinary integration", Synthese, Vol. 190 No. 11, pp. 1865-1879.

Jones, M. (2012), "Teaching Research Across Disciplines: Interdisciplinarity and Information Literacy", in Gibson, C. and Mack, D. (Eds), Interdisciplinarity and Academic Libraries, Association of College and Research Libraries, Chicago,IL, pp. 167-181.

Kapitzke, C. (2003), "Information literacy: A positivist epistemology and a politics of outformation", Educational theory, Vol. 53 No. 1, pp. 37-53.

Kjellberg, S. (2009), "Scholarly blogging practice as situated genre: an analytical framework based on genre theory", Information Research, Vol 14 No 3.

Klein, J. T. (1990), Interdisciplinarity : history, theory, and practice, Wayne State University Press, Detroit, MI.

Levina, N., and Orlikowski, W. J. (2009), "Understanding shifting power relations within and across organizations: A critical genre analysis", Academy of Management Journal, No. 52 Vol. 4, pp. 672-703.

Latour, B., and Woolgar, S. (1986), Laboratory life: The construction of scientific facts, Princeton University Press, Princeton, NJ..

Limberg, L., and Alexandersson, M. (2009), "Learning and information seeking", in Bates, M. J. and Maack, M. N. (Eds.), Encyclopedia of Library and Information Sciences (3 ed.), Taylor and Francis, New York, NY, pp. 3252-3262.

Lloyd, A. (2010a), "Lessons from the workplace: Understanding information literacy as practice", in Lloyd, A. and Talja, S. (Eds.), Practising information literacy: bringing theories of learning, practice and information literacy together, Centre for Information Studies, Wagga Wagga, pp. 29-49.

Lloyd, A. (2010b), "Framing information literacy as information practice: Site ontology and practice theory", Journal of documentation, Vol. 66 No. 2, pp. 245-258.

Lloyd, A. (2012), "Information literacy as a socially enacted practice. Sensitising themes for an emerging perspective of people-in-practice", Journal of documentation, Vol. 68 No 6, pp. $772-$ 783.

Lupton, M., and Bruce, C. (2010), "Windows on information literacy worlds: Generic, situated and transformative perspectives", in Lloyd, A. and Talja, S. (Eds.), Practising information literacy:

Bringing theories of learning, practice and information literacy together, Centre for Information Studies, Wagga Wagga, N.S.W., pp. 3-27.

Madsen, D. (2012), "Interdisciplinarity in the information field", Proceedings of the American Society for Information Science and Technology, Vol. 49 No. 1, pp. 1-7. 
Eystein Gullbekk 2016. Published in Journal of Documentation, vol:72, iss:4 http://dx.doi.org/10.1108/JDOC-08-2015-0101

McKenzie, P.J. (2015), "Genre and typified activities in informing and personal information management", in Andersen, J. (Ed.), Genre theory in information studies, Emerald, Bingley, pp. 67-90.

Miller, C. R. (1984), "Genre as social action", Quarterly journal of speech, Vol 70 No. 2, pp. 151-167.

Moring, C. E., and Lloyd, A. (2013), "Analytical implications of using practice theory in workplace information literacy research", Information Research, Vol. 18 No. 3.

Pawley, C. (2003), "Information Literacy: A Contradictory Coupling". Library Quarterly, Vol. 73 No. 4, pp. 422-452.

Pilerot, O. (2013), "A practice theoretical exploration of information sharing and trust in a dispersed community of design scholars", Information Research, Vol. 18 No. 4.

Pilerot, O. (2014), "Making design researchers' information sharing visible through material objects", Journal of the Association for Information Science and Technology, Vol. 65 No. 10, pp. 20062016.

Pilerot, O., and Limberg, L. (2011), "Information sharing as a means to reach collective understanding: A study of design scholars' information practices", Journal of Documentation, Vol 67 No 2, pp. 312-333.

Pilerot, O. and Limberg, L. (2015), "The Enactment of Information Literacy: An Exploratory Study Among Interdisciplinary PhD Students", in Kurbanoğlu, S., Boustany, J., Špiranec, S., et al. (Eds), Information Literacy: Moving Toward Sustainability, ECIL, Springer International Publishing, Cham, Tallinn, pp. 478-488. Publishing, Cham, Tallinn, pp. 478-488.

Schatzki, T. R. (2002), The site of the social: a philosophical account of the constitution of social life and change, Pennsylvania State University Press, Philadelphia, PA.

Schatzki, T. R. (2005), "Peripheral vision: the sites of organizations", Organization Studies, Vol. 26 No. 3, pp. 465-484.

Schatzki, T.R. (2011), "Where the action is (on large social phenomena such as sociotechnical regimes)", Working Paper No. 1, Sustainable Practices Research Group, Manchester, November, available at: www.sprg.ac.uk/publications-amp-presentations/discussionpapers/schatzkipractice-theory-macro-phenomena-sociotechnical-regimes (accessed 20 January 2015).

Schreiber, T. (2014), "Conceptualizing students' written assignments in the context of information literacy and Schatzki's practice theory", Journal of documentation, Vol. 70 No. 3, 346-363.

Schryer, C., F. . (2009), "Genre theory and research", in Bates, M. J. and Maack, M. N. (Eds.), Encyclopedia of Library and Information Sciences (3. ed.), Taylor and Francis, New York, pp. 1934-1942.

Schryer, C.F., Lingard, L., Spafford, M. and Garwood, K. (2003), "Structure and agency in medical case presentations", in Bazerman, C. and Russel, D.R. (Eds), Writing Selves/Writing Societies: Research from Activity Perspectives, The WAC Clearinghouse, Fort Collins, CO, pp. 62-96, available at: http://wac.colostate.edu/books/selves_societies/ (accessed 20 January 2015).

Simmons, M. H. (2005), "Librarians as disciplinary discourse mediators: Using genre theory to move toward critical information literacy", portal: Libraries and the Academy, Vol. 5 No. 3, 297-311.

Sundin, O. (2002), "Nurses' information seeking and use as participation in occupational communities", The New Review of Information Behaviour Research: Studies of Information Seeking in Context, Vol. 3, pp. 187-202.

Sundin, O. (2008), "Negotiations on information-seeking expertise: a study of web-based tutorials for information literacy", Journal of documentation, Vol. 64 No. 1, pp. 24-44.

Sundin, O. (2011), "Janitors of knowledge: constructing knowledge in the everyday life of Wikipedia editors", Journal of Documentation, Vol. 67 No. 5, pp. 840-862.

Sundin, O., Limberg, L., and Lundh, A. (2008), "Constructing librarians' information literacy expertise in the domain of nursing", Journal of Librarianship and Information Science, Vol. 40 No. 1, pp. 21-30. 
Thune, T., Kyvik, S., Sörlin, S., Olsen, T. B., Vabø, A., and Tømte, C. (2012). PhD education in a knowledge society. Nordic Institute for Studies in Innovation, Oslo.

Tuominen, K., Savolainen, R., and Talja, S. (2005), "Information Literacy as a Sociotechnical Practice", The Library Quarterly, Vol. 75 No. 3, pp.329-345.

Wenger, E. (1998), Communities of practice: Learning, meaning, and identity, Cambridge university press, Cambridge, MA.

Whitworth, A. (2014), Radical Information Literacy: Reclaiming the political heart of the IL movement, Chandos, Oxford. 